\title{
Serotonin Function Following Remission from Bulimia Nervosa
}

\author{
Barbara E. Wolfe, Ph.D., R.N., Eran D. Metzger, M.D., Jeffrey M. Levine, M.D., \\ Dianne M. Finkelstein, Ph.D., Thomas B. Cooper, M.A., and David C. Jimerson, M.D.
}

\begin{abstract}
Abnormal serotonergic regulation in bulimia nervosa is thought to contribute to recurrent binge eating, depressed mood, and impulsivity. To follow-up on previous studies showing decreased neuroendocrine responses in symptomatic patients, this study assessed serotoninmediated prolactin responses in individuals who had remitted from bulimia nervosa. Subjects included 21 women with a history of bulimia nervosa and 21 healthy female controls, as well as an additional comparison group of 19 women with current bulimia nervosa. Placebo-controlled neuroendocrine response studies utilized a single oral dose $(60 \mathrm{mg})$ of the indirect serotonin agonist d,l-fenfluramine. For the bulimia nervosa remitted group, the fenfluramine-
\end{abstract}

stimulated elevation in serum prolactin concentration was not significantly different from the response in healthy controls, but was significantly larger than the response in patients with current bulimia nervosa $(\mathrm{p}<.01)$. These findings suggest that diminished serotonergic neuroendocrine responsiveness in bulimia nervosa reflects a state-related abnormality. The results are discussed in relationship to recent reports indicating that some alterations in central nervous system serotonin regulation may persist in symptomatically recovered individuals.

[Neuropsychopharmacology 22:257-263, 2000] (C) 2000 American College of Neuropsychopharmacology. Published by Elsevier Science Inc.
KEY WORDS: Serotonin; Bulimia nervosa; Eating disorders; Neuroendocrine

Impaired serotonergic responsiveness may play a physiological role in symptoms of bulimia nervosa. Thus, it is thought that diminished post-ingestive satiety creates a predisposition to large binge meals in this disorder (Mitchell and Laine 1985; LaChaussee et al. 1992; Kissil-

From the Department of Psychiatry, Beth Israel Deaconess Medical Center, and Department of Psychiatry, Harvard Medical School, Boston, MA (BEW, EDM, DCJ); Department of Psychiatry, Yale University School of Medicine, New Haven, CT (JML); Department of Biostatistics, Harvard School of Public Health, Boston, MA (DMF); and Nathan Kline Institute for Psycshiatric Research (TBC), Orangeburg, NY, and New York State Psychiatric Institute, College of Physicians \& Surgeons (TBC), Columbia University, New York, NY.

Address correspondence to: Dr. Wolfe, Department of Psychiatry, Beth Israel Deaconess Medical Center, 330 Brookline Avenue, Boston, MA 02215.

Received November 23, 1998; revised August 5, 1999; accepted September 9, 1999. eff et al. 1996). Studies in laboratory animals and in human volunteers have demonstrated that reduction in central nervous system (CNS) serotonergic function results in increased meal size (Blundell and Hill 1987; Goodall and Silverstone 1988; Leibowitz et al. 1990; Tecott et al. 1995). Patterns of mood lability, depression and impulsivity observed in bulimia nervosa (Jimerson et al. 1990; Wolfe et al. 1994a) may also reflect CNS serotonergic dysregulation (Cowen 1993; Coccaro et al. 1997). Conversely, the efficacy of antidepressant medications in decreasing frequency of binge eating episodes in bulimia nervosa (Jimerson et al. 1996) may reflect enhanced efficiency of signal transduction at serotonergic synapses (Blier and de Montigny 1994).

Psychobiological investigations comparing patients with bulimia nervosa with healthy control subjects have demonstrated diminished CNS serotonergic activity, as manifested by blunted neuroendocrine responses to single dose administration of a serotonergic agonist (Brewerton et al. 1992; Halmi et al. 1993; Goldbloom et 
al. 1996; Jimerson et al. 1997; Levitan et al. 1997; Monteleone et al. 1998). Additionally, previous studies have shown an inverse correlation between symptom severity, as reflected in frequency of binge eating episodes, and measures of serotonergic responsiveness (Jimerson et al. 1992, 1997). These observations are consistent with the hypothesis that diminished responsiveness in CNS serotonergic pathways contributes to the symptoms of this disorder.

The goal of the current study was to test the related hypothesis that individuals who have recovered from bulimia nervosa have increased CNS serotonergic responsiveness in comparison to currently symptomatic individuals. The primary outcome measure for this assessment was the increase in serum prolactin concentration following placebo-controlled, single-dose administration of the indirect serotonin agonist d,l-fenfluramine.

\section{SUBJECTS AND METHOD}

\section{Subjects}

Subjects were recruited through media advertisements and from local outpatient eating disorder programs. Research diagnostic assessments were made by a trained interviewer (BEW) using the Schedule for Affective Disorders and Schizophrenia-Life Version (SADS-L) (Endicott and Spitzer 1978) and Research Diagnostic Criteria (Spitzer et al. 1978), modified to include criteria for bulimia nervosa based on the Diagnostic and Statistical Manual of Mental Disorders, Third Edition, Revised (DSM-III-R) (American Psychiatric Association 1987).

The syndrome-remitted group $\left(\mathrm{BN}_{\text {remitted }}\right)$ included 21 women who had previously met criteria for bulimia nervosa based on DSM-III-R, with the additional requirement of a history of binge eating and purging (by self-induced vomiting or laxative use) on average twice per week or more frequently over six months. Additional inclusion criteria for the $\mathrm{BN}_{\text {remitted }}$ group required that participants had experienced less than one binge / purge episode per month for the previous three months and had regular menstrual cycles. Of the 21 remitted subjects, 16 reported complete abstinence from binge eating for three months or longer prior to study.

The control group included 21 healthy female volunteers. A second comparison group included 19 non-hospitalized, medication-free patients with current symptoms of DSM-III-R bulimia nervosa $\left(\mathrm{BN}_{\text {active }}\right)$, with the additional criteria of binge eating and purging (by selfinduced vomiting or laxative use) on average at least twice per week over the previous six months. The $\mathrm{BN}_{\text {active }}$ group included one patient with secondary amenorrhea. Neuroendocrine data for a subset of the $\mathrm{BN}_{\text {active }}$ and control groups has been previously reported (Jimerson et al. 1997).
Based on diagnostic assessment using the SADS-L, the patient groups were free of major depression, alcoholism, and substance abuse for at least six months prior to study, and controls were free of current and past history of an eating disorder or other major psychiatric disorder. Individuals in the patient groups had not been in treatment with psychotropic medications for at least eight weeks prior to study. Subjects were within a normal body weight range adjusted for height (body mass index between 18 and $26 \mathrm{~kg} / \mathrm{m}^{2}$ ) (Society of Actuaries and Association of Life Insurance Medical Directors of America 1980), were free of concurrent medical illness, and were abstinent from alcohol for at least one week prior to study. Subjects had not taken oral contraceptives and had not been pregnant during the six months prior to study. All subjects received a complete description of study procedures and gave written informed consent.

\section{Procedures}

Studies were conducted after overnight fast and bed rest on a General Clinical Research Center inpatient unit in a single-blind, placebo-first, fixed order design during the follicular phase of subjects' menstrual cycle.

Blood samples for measurement of prolactin concentration were obtained at baseline and at five hourly intervals following oral administration of d,l-fenfluramine $(60 \mathrm{mg})$ or matched placebo at 9:00 a.m. Plasma total fenfluramine (fenfluramine plus norfenfluramine) concentrations were measured at five hourly time points following drug administration. To assess menstrual cycle and metabolic status, baseline blood samples were collected for estradiol, progesterone, cortisol, thyroid hormone and amino acid measurements. Percent lean body mass was calculated based on skin fold measurements (Durnin and Womersley 1974; Lohman et al. 1988).

Baseline behavioral measures included self-ratings on the Eating Attitudes Test (Garner et al. 1982), Beck Depression Inventory (Beck and Steer 1987), as well as the Spielberger State-Trait Anxiety Inventory (Spielberger 1983), and investigator ratings (BEW, EDM) on the 17-item Hamilton Depression Rating Scale (Hamilton 1960). Side effects including "tiredness," "nausea," "stomachache," "headache," and "decreased appetite" were assessed on a five point self-rated Likert scale at baseline and two hours and five hours following drug / placebo administration.

\section{Hormone and Amino Acid Assays}

Serum prolactin levels were measured by fluoroimmunoassay (DELFIA kit; Wallac Inc., Gaithersberg, MD). Plasma concentrations of fenfluramine and norfenfluramine were measured by gas chromatography (Krebs et al. 1984). Serum estradiol, progesterone, cortisol and 
thyroid hormone levels were measured by radioimmunoassay. Plasma tryptophan was measured by a fluorometric assay (Denckla and Dewey 1967) and large neutral amino acids (LNAA) (valine, methionine, leucine, isoleucine, tyrosine, and phenylalanine) were measured by high pressure liquid chromatography.

\section{Data Analysis}

Average prolactin response was calculated as the mean increase in prolactin concentration over baseline levels at the $2,3,4$, and 5 hour post-fenfluramine time points. Prolactin peak response was calculated as the maximal increase in hormone levels over baseline. For these calculations, the prolactin concentration at each post-drug time point on the active study day was adjusted for the percent change from baseline at the comparable time on the placebo day. Plasma average fenfluramine levels were calculated as the sum of fenfluramine plus norfenfluramine concentrations averaged over five hourly measurements.

Group data are summarized as mean \pm standard deviation (SD). Statistical significance was defined as $p<.05$ based on two-sided significance levels. Baseline data for the three study groups were compared by analysis of variance. Variables not normally distributed (Kolmogorov-Smirnov test) were square root- or log-transformed, or else were analyzed by Kruskal-Wallis test. Neuroendocrine responses were compared across groups by analysis of covariance, adjusting for plasma average fenfluramine concentration when the covariate term reached significance. For pre-planned contrasts comparing the $\mathrm{BN}_{\text {remitted }}$ group with the control and $\mathrm{BN}_{\text {active }}$ groups, statistical significance was set at $p<.025$.

Relationships between baseline measures and prolactin response were assessed by correlational analysis. Baseline serum prolactin and cortisol levels for paired active and placebo days were compared by repeated measures analysis of variance. Side effect ratings for the two study days, calculated as change from baseline, were compared by Wilcoxon matched-pairs signedranks test. For multiple comparisons, Bonferroni-adjusted significance levels were used. Statistical calculations were made using SPSS ${ }^{\circledR} 9.0$ (1999).

\section{RESULTS}

\section{Subject Characteristics}

Individuals in the $\mathrm{BN}_{\text {remitted }}$ group had most recently met full DSM-III-R criteria for the disorder $40 \pm 29$ months prior to study (range 4 to 126 months). For the $\mathrm{BN}_{\text {active }}$ group, average frequencies of binge eating and self-induced vomiting over the four weeks prior to study were $6.6 \pm 3.7$ and $7.0 \pm 4.9$ episodes per week, respectively. Season of study did not differ across subject groups $\left(X^{2}=4.91, \mathrm{df}=6, p=\mathrm{ns}\right)$.

For descriptive and behavioral variables, there was a significant group effect for the Eating Attitudes Test, Hamilton Depression Rating, Beck Depression Inventory, and Spielberger State and Trait Anxiety Inventories (Table 1). One or more previous episodes of major depression were identified in seven individuals $(33 \%)$ in the $\mathrm{BN}_{\text {remitted }}$ group and six patients (32\%) in the $\mathrm{BN}_{\text {active }}$ group. A history of anorexia nervosa was present in six $(29 \%)$ individuals in the $\mathrm{BN}_{\text {remitted }}$ group and 10 patients $(53 \%)$ in the $\mathrm{BN}_{\text {active }}$ group. Based on SADS-L data, one $\mathrm{BN}_{\text {remitted }}$ individual met criteria for current phobic disorder and two met criteria for previous generalized anxiety disorder. One $\mathrm{BN}_{\text {active }}$ individual met criteria for current generalized anxiety disorder. No subjects met criteria for current or past panic disorder or obsessive compulsive disorder.

Table 1. Descriptive Characteristics and Baseline Behavioral Ratings for Study Subjects

\begin{tabular}{|c|c|c|c|c|c|c|}
\hline & \multicolumn{2}{|c|}{$\mathbf{B N}_{\text {remitted }}(n=21)$} & \multicolumn{2}{|c|}{ Control $(n=21)$} & \multicolumn{2}{|c|}{$\mathrm{BN}_{\text {active }}(n=19)$} \\
\hline & Mean & $S D$ & Mean & $S D$ & Mean & $S D$ \\
\hline Age $^{\#}$ & 24.9 & 4.1 & 22.9 & 3.4 & 23.6 & 3.8 \\
\hline Weight (kg) & 58.9 & 7.8 & 58.1 & 7.0 & 59.9 & 6.8 \\
\hline Lean body mass (\%) & 71.9 & 4.0 & 72.5 & 5.0 & 73.6 & 5.7 \\
\hline$\%$ Expected body weight $\$$ & 99.4 & 9.5 & 98.8 & 8.8 & 99.9 & 9.5 \\
\hline Body mass index & 21.8 & 2.0 & 21.5 & 2.0 & 21.7 & 2.2 \\
\hline Menstrual cycle day ${ }^{\S}$ & 8.0 & 2.0 & 8.0 & 3.0 & 9.0 & $3.0^{+}$ \\
\hline Eating attitudes test ${ }^{\S}$ & 8.5 & $6.9^{\mathrm{a} * * *, \mathrm{~b} * * *}$ & 3.2 & 3.3 & 34.7 & $6.7^{c * * *}$ \\
\hline Hamilton depression rating ${ }^{\#}$ & 2.4 & $2.8^{\mathrm{a} * *}$ & 0.4 & 0.6 & 4.2 & $4.2^{c * * *}$ \\
\hline Beck Depression Inventory\# & 2.8 & $4.3^{\mathrm{a} * *}$ & 0.2 & 0.5 & 5.3 & $4.7^{(* * *}$ \\
\hline Spielberger State Anxiety Inventory & 30.0 & $8.1^{\mathrm{b} *}$ & 25.4 & 4.6 & 36.1 & $9.2^{c * * *}$ \\
\hline Spielberger Trait Anxiety Inventory & 36.9 & $9.7^{\mathrm{a} * * *, \mathrm{~b} * *}$ & 26.5 & 4.2 & 45.2 & $11.8^{\mathrm{c} * * *}$ \\
\hline
\end{tabular}

Contrasts: $\mathrm{a}=\mathrm{BN}_{\text {remitted }}$ vs. Control; $\mathrm{b}=\mathrm{BN}_{\text {remitted }}$ vs. $\mathrm{BN}_{\text {active}} ; \mathrm{c}=\mathrm{BN}_{\text {active }}$ vs. Control.

$\S$ Variable transformed prior to ANOVA; ${ }^{*}$ Kruskal-Wallis test; ${ }^{\dagger} n=18$, one patient amenorrheic.

${ }^{*} p<.025 ;{ }^{* *} p<.01 ;{ }^{* * *} p<.001$. 


\section{Serum Prolactin Response to Fenfluramine Challenge}

Baseline serum prolactin concentrations for the $\mathrm{BN}_{\text {remitted }}$ group were not significantly different from levels for the comparison groups (Table 2). At the four hour time point on the placebo day (corresponding to the time of maximal hormone response on the active study day), the diurnal decrease in prolactin level was not significantly different for the $\mathrm{BN}_{\text {remitted }}$ group $(19 \pm 25 \%)$, the healthy controls $(20 \pm 50 \%)$, and the $\mathrm{BN}_{\text {active }}$ group (21 $\left.\pm 36 \%\right)$.

Plasma fenfluramine mean concentration for the $\mathrm{BN}_{\text {remitted }}$ group (344 $\left.\pm 97 \mathrm{nmol} / \mathrm{L}\right)$ was not significantly different from values for the controls $(361 \pm 75 \mathrm{nmol} / \mathrm{L})$ or the $\mathrm{BN}_{\text {active }}$ group $(309 \pm 107 \mathrm{nmol} / \mathrm{L})$. For the combined groups, prolactin average response was correlated with plasma fenfluramine concentration $(\mathrm{r}=0.338, \mathrm{df}=$ $59, p=.008)$, with a trend for an association between prolactin peak response and drug concentration $(p=.07)$.

For prolactin average response, analysis of covariance demonstrated a significant main effect for study group ( $p=.019)$, as well as for the fenfluramine concentration covariate term $(p=.030)$. The prolactin average response for the $\mathrm{BN}_{\text {remitted }}$ group was significantly greater than for currently symptomatic patients, and not significantly different from responses for healthy controls (Figure 1A). Similarly, for the $16 \mathrm{BN}_{\text {remitted }}$ individuals who had maintained complete abstinence from binge eating and purging episodes for at least three months prior to study, the prolactin response was significantly greater than for $\mathrm{BN}_{\text {active }}$ individuals $(p=.004)$, and not significantly different from that for controls.

For prolactin peak response, the analysis of covariance found a significant main effect for study group $(p=$ .004). The prolactin peak response for the $\mathrm{BN}_{\text {remitted }}$ group was significantly greater than for currently symptomatic patients (Figure 1B). Similar results were obtained for the subgroup of binge-abstinent individuals. Consistent with previous results, the prolactin response for the $\mathrm{BN}_{\text {active }}$ group was blunted in comparison to the control group's response (Figures 1A and 1B).

\section{Baseline Blood Hormone Levels}

For baseline hormone measurements, analysis of variance showed a significant group effect for serum prolactin, cortisol, and free thyroxine (Table 2). Repeated measures analysis of variance did not demonstrate significant differences in baseline serum prolactin or cortisol concentrations between the active and placebo study days. One individual in each group had estradiol levels more than two standard deviations greater than the group mean, and one individual in the $\mathrm{BN}_{\text {remitted }}$ and control groups had similarly elevated progesterone levels. When analyses were repeated excluding these individuals, differences in prolactin response between study groups remained similar to those presented above. Fenfluramine-stimulated prolactin response was not significantly correlated with age or with any of the baseline biological measurements.

\section{Behavioral Ratings}

Duration of remission for the $\mathrm{BN}_{\text {remitted }}$ group was significantly correlated with age $(\mathrm{r}=0.49, \mathrm{df}=19, p=$ .032). Prolactin response for the $\mathrm{BN}_{\text {remitted }}$ group was not significantly correlated with duration of remission, controlling for age, nor with any of the behavioral ratings. Within the $\mathrm{BN}_{\text {remitted }}$ and $\mathrm{BN}_{\text {active }}$ groups, prolactin response did not differ significantly for the subgroups with and without a history of anorexia nervosa.

Fenfluramine administration significantly decreased appetite ratings at the five hour time point for the combined sample $(\mathrm{z}=3.11, p=.002)$, and for the $\mathrm{BN}_{\text {remitted }}$ group taken separately $(\mathrm{z}=3.02, p=.002)$. Ratings for other side effects were not significantly different between the two study days.

Table 2. Baseline Blood Hormone and Amino Acid Levels on Active Study Day

\begin{tabular}{|c|c|c|c|c|c|c|}
\hline & \multicolumn{2}{|c|}{$\mathrm{BN}_{\text {remitted }}(n=21)$} & \multicolumn{2}{|c|}{ Control $(n=21)$} & \multicolumn{2}{|c|}{$\mathrm{BN}_{\text {active }}(n=19)$} \\
\hline & Mean & $S D$ & Mean & $S D$ & Mean & $S D$ \\
\hline Prolactin $(\mu \mathrm{g} / \mathrm{L})$ & 6.6 & 1.9 & 7.5 & 2.3 & 5.4 & $1.8^{\mathrm{c} * *}$ \\
\hline Estradiol $(\mathrm{pg} / \mathrm{mL}) \S$ & 68.4 & $46.8^{+}$ & 50.0 & $29.2^{+}$ & 42.5 & $35.0^{+}$ \\
\hline Progesterone $(\mathrm{ng} / \mathrm{mL}) \S$ & 0.62 & $0.60^{+}$ & 0.49 & $0.22^{+}$ & 0.56 & 0.31 \\
\hline Cortisol $(\mu \mathrm{g} / \mathrm{dL})^{\S}$ & 13.7 & $4.1^{\mathrm{b} * *}$ & 15.4 & 4.5 & 18.1 & 5.5 \\
\hline Triiodothyronine (ng/dL) & 79.8 & 14.9 & 89.4 & 20.4 & 76.2 & 16.5 \\
\hline Free thyroxine (ng/dL) & 0.76 & $0.18^{\mathrm{a} * *}$ & 0.93 & 0.18 & 0.70 & $0.19^{c * * *}$ \\
\hline Thyrotropin $(\mu \mathrm{U} / \mathrm{mL})$ & 1.31 & 0.65 & 1.22 & 0.49 & 0.92 & 0.40 \\
\hline Total tryptophan (nmol/mL) & 45.7 & 6.6 & 47.8 & 7.3 & 46.0 & 8.3 \\
\hline TRP / ¿LNAA ratio & 0.091 & 0.016 & 0.091 & 0.013 & 0.090 & 0.015 \\
\hline
\end{tabular}

Contrasts: $\mathrm{a}=\mathrm{BN}_{\text {remitted }}$ Vs. Control; $\mathrm{b}=\mathrm{BN}_{\text {remitted }}$ vs. $\mathrm{BN}_{\text {active }} ; \mathrm{c}=\mathrm{BN}_{\text {active }}$ vs. Control.

$\S$ Variable transformed prior to ANOVA; ${ }^{\dagger}$ Mean values exclude one outlier value in designated subject groups.

${ }^{* *} p<.01 ;{ }^{* * *} p<.001$. 

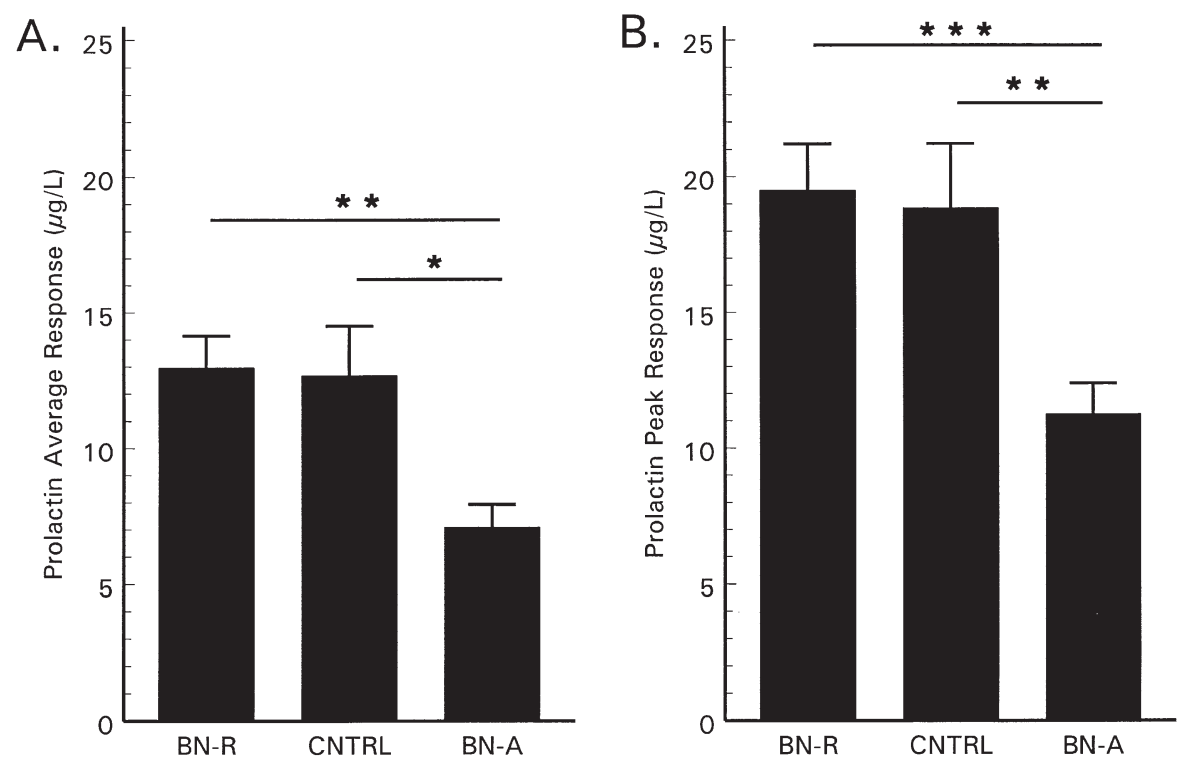

Figure 1. Placebo-adjusted serum prolactin response following administration of $d, 1$-fenfluramine in 21 individuals recovered from bulimia nervosa (BN-R), 21 healthy controls (CNTRL), and 19 subjects with current bulimia nervosa (BN-A). Prolactin response (mean \pm SEM) is shown as average increase over baseline (A) and peak increase over baseline (B). Statistical significance: ${ }^{*} p<.025 ;{ }^{* *} p<.01 ;{ }^{* * *} p<.005$.

\section{DISCUSSION}

Results of this study show that individuals who have recovered from bulimia nervosa have significantly increased serotonergic neuroendocrine responsiveness in comparison to patients with current symptoms of the disorder. Given the behavioral effects of serotonin noted in the Introduction, restoration of CNS serotonergic responsiveness may play a role in recovery from the disorder. This possibility is supported by a recent report that individuals recovered from bulimia nervosa experienced a transient return of eating disorder related symptoms when CNS serotonin function was diminished by administration of a tryptophan-deficient amino acid mixture (Smith et al. 1999).

For the $\mathrm{BN}_{\text {remitted }}$ group, neuroendocrine responses were not significantly different from results for healthy controls, in agreement with preliminary findings (Wolfe et al. 1994b). These results are consistent with a recent report indicating that neuroendocrine responses to the serotonin agonist m-chlorophenylpiperazine (mCPP) were not significantly different for patients recovered from bulimia nervosa and healthy controls (Kaye et al. 1998).

In evaluating these neuroendocrine results, it is important to note that the prolactin response to d,l-fenfluramine provides an index of localized synaptic throughput in hypothalamic serotonergic pathways, reflecting the drug's enhancement of pre-synaptic transmitter release, blockade of pre-synaptic re-uptake, and possibly stimulation of post-synaptic receptors (Garattini et al. 1986). In contrast, several recent studies have reported differences in other measures of CNS serotonin function in individuals recovered from bulimia nervosa in comparison to healthy controls. Thus, recovered individuals had significantly elevated serotonin metabolite concen- trations in cerebrospinal fluid in comparison to controls, and increased sensitivity to several behavioral effects of $\mathrm{mCPP}$, including feelings of anxiety and "difficulty functioning" (Kaye et al. 1998). Additionally, following administration of a tryptophan-deficient amino acid mixture, individuals who had recovered from bulimia nervosa showed increased sensitivity to eating disorder-related behavioral effects in comparison to controls (Smith et al. 1999). Based on these studies, it is possible that normal function is restored in hypothalamic serotonergic pathways following recovery from bulimia nervosa, while dysregulation persists in other CNS serotonergic pathways.

A second possibility is that restoration of hypothalamic-pituitary neuroendocrine responsiveness in the recovered individuals is reflective of compensatory adaptations occurring more widely in CNS serotonergic pathways. For example, increased pre-synaptic serotonin release could compensate for impaired post-synaptic receptor responsiveness. In this case, persisting abnormalities in serotonin function may become apparent only when the systems are challenged, as in the case of dieting (Anderson et al. 1989) or the administration of a tryptophan-deficient amino acid mixture (Weltzin et al. 1995; Smith et al. 1999). Further studies are needed to clarify the regulation of serotonergic pathways involved in the modulation of satiety, mood, anxiety and related behavioral dimensions following recovery from bulimia nervosa.

Measurement of baseline serum hormone levels revealed several differences across study groups. Free thyroxine levels for the $\mathrm{BN}_{\text {remitted }}$ were significantly lower than control levels. The finding of significantly reduced free thyroxine and baseline prolactin levels in the $\mathrm{BN}_{\text {active }}$ group is consistent with previous reports (Pirke et al. 1985; Levy et al. 1988; Obarzanek et al. 1991; 
Weltzin et al. 1991; Brewerton et al. 1992; Jimerson et al. 1997). It is possible that nutritional factors may have contributed to reductions in thyroid hormone levels, even though study groups were matched for body weight. These observations merit further study, given that decreased thyroid function has been associated with diminished responsiveness in CNS serotonergic pathways (Cleare et al. 1995). The reduction in baseline cortisol levels in the remitted individuals in comparison to the active bulimia nervosa group may also play a role in differential serotonergic responses, given that variations in glucocorticoid levels can influence CNS serotonin receptor function (Fernandes et al. 1997). The finding that blood tryptophan levels and the ratio of tryptophan to other large neutral amino acids were not significantly different across study groups is consistent with previous reports (Wolfe et al. 1997; Kaye et al. 1998; Smith et al. 1999).

A potential limitation of the present study is that criteria for remission from bulimia nervosa were based primarily on recovery from binge eating and purging behaviors. The $\mathrm{BN}_{\text {remitted }}$ group had ratings on the Eating Attitudes Test that were comparable to scores for female university students (9.9 \pm 9.2) (Garner et al. 1982) and were significantly lower than for symptomatic patients, although they were statistically elevated in comparison to the control group. Self-ratings of depression and anxiety for the $\mathrm{BN}_{\text {remitted }}$ group, also elevated in comparison to control values, were similar to or slightly lower than ratings for recovered individuals described in previous studies (Kaye et al. 1998; Smith et al. 1999). As noted by others, dieting and other patterns of abnormal eating, associated with modest elevations on ratings of eating disorder symptomatology, tend to persist after binge eating and purging have remitted (Oldman et al. 1995; Kaye et al. 1998). Thus, it is possible that individuals in the $\mathrm{BN}_{\text {remitted }}$ group had persistent abnormalities in dietary patterns which may have influenced neuroendocrine response patterns.

Another potential limitation of the current study was the cross-sectional design, which did not incorporate repeated neuroendocrine testing in individual subjects followed longitudinally from illness to recovery. Previous symptom patterns for the remitted individuals appeared to resemble clinical characteristics of the currently symptomatic patients, who did show diminished prolactin responses. It would be of interest in future studies to assess whether restoration of serotonergic neuroendocrine responsiveness parallels the decreased risk for relapse observed six months following clinical remission (Olmsted et al. 1994).

In summary, results of this study indicate that recovery from bulimia nervosa is associated with restoration of normal responsiveness in neuroendocrine-related serotonergic pathways. Additional studies are needed to evaluate these results in relationship to other evidence for CNS serotonergic dysregulation in symptomatically recovered individuals.

\section{ACKNOWLEDGMENTS}

This work was supported in part by USPHS grants K07 MH00965 (Dr. Wolfe) and R01 MH45466 (Dr. Jimerson) from the National Institute of Mental Health, and grant RR01032 to the General Clinical Research Center (GCRC) at Beth Israel Deaconess Medical Center from the National Center for Research Resources, National Institutes of Health. The authors gratefully acknowledge the assistance of the nursing, nutrition and laboratory staff of the GCRC at Beth Israel Deaconess Medical Center. A.H. Robbins Co. / Wyeth-Ayerst Laboratories provided d,l-fenfluramine and placebo tablets.

\section{REFERENCES}

American Psychiatric Association (1987): Diagnostic and Statistical Manual of Mental Disorders, 3rd ed, Revised. Washington DC, American Psychiatric Press

Anderson IM, Crook WS, Gartside SE, Parry-Billings M, Newsholme EA, Cowen PJ (1989): Effect of moderate weight loss on prolactin secretion in normal volunteers. Psychiatry Res 29:161-167

Beck AT, Steer RT (1987): Beck Depression Inventory Manual. New York, NY, Psychological Corporation Harcourt Brace Jovanovich

Blier P, de Montigny C (1994): Current advances and trends in the treatment of depression. Trends Pharmacol Sci $15: 220-226$

Blundell JE, Hill AJ (1987): Serotoninergic modulation of the pattern of eating and the profile of hunger-satiety in humans. Int J Obes 11 (Suppl 3):141-155

Brewerton TD, Mueller EA, Lesem MD, Brandt HA, Quearry B, George DT, Murphy DL, Jimerson DC (1992): Neuroendocrine responses to $\mathrm{m}$-chlorophenylpiperazine and L-tryptophan in bulimia. Arch Gen Psychiatry 49:852-861

Cleare AJ, McGregor A, O’Keane V (1995): Neuroendocrine evidence for an association between hypothyroidism, reduced central 5-HT activity and depression. Clin Endocrinol 43:713-719

Coccaro EF, Kavoussi RJ, Cooper TB, Hauger RL (1997): Central serotonin activity and aggression: Inverse relationship with prolactin response to $d$-fenfluramine, but not CSF 5-HIAA concentration, in human subjects. Am J Psychiatry 154:1430-1435

Cowen PJ (1993): Serotonin receptor subtypes in depression: Evidence from studies in neuroendocrine regulation. Clin Neuropharmacol 16:S6-S18

Denckla WD, Dewey HK (1967): The determination of tryptophan in plasma, liver, and urine. J Lab Clin Med 69:160-169

Durnin JVGA, Womersley J (1974): Body fat assessed from total body density and its estimation from skinfold thickness: Measurements on 481 men and women aged from 16 to 72 years. Br J Nutr 32:77-97

Endicott J, Spitzer RL (1978): A diagnostic interview: The 
schedule for affective disorders and schizophrenia. Arch Gen Psychiatry 35:837-844

Fernandes C, McKittrick CR, File SE, McEwen BS (1997): Decreased 5-HT1A and increased 5-HT2A receptor binding after chronic corticosterone associated with a behavioural indication of depression but not anxiety. Psychoneuroendocrinology 22:477-491

Garattini S, Mennini T, Bendotti C, Invernizzi R, Samanin R (1986): Neurochemical mechanism of action of drugs which modify feeding via the serotoninergic system. Appetite 7 (Suppl):15-38

Garner DM, Olmsted MP, Bohr Y, Garfinkel PE (1982): The Eating Attitudes Test: Psychometric features and clinical correlates. Psychol Med 12:871-878

Goldbloom DS, Garfinkel PE, Katz R, Brown GM (1996): The hormonal response to intravenous 5-hydroxytryptophan in bulimia nervosa. J Psychosom Res 40:289-297

Goodall E, Silverstone T (1988): Differential effect of d-fenfluramine and metergoline on food intake in human subjects. Appetite 11:215-228

Halmi KA, McBride PA, Sunday SR (1993): Serotonin responsivity and hunger and satiety in eating disorders. Adv Biosci 90:123-131

Hamilton M (1960): A rating scale for depression. J Neurol Neurosurg Psychiatry 23:56-62

Jimerson DC, Lesem MD, Kaye WH, Brewerton TD (1992): Low serotonin and dopamine metabolite concentrations in cerebrospinal fluid from bulimic patients with frequent binge episodes. Arch Gen Psychiatry 49:132-138

Jimerson DC, Lesem MD, Kaye WH, Hegg AP, Brewerton TD (1990): Eating disorders and depression: Is there a serotonin connection? Biol Psychiatry 28:443-454

Jimerson DC, Wolfe BE, Brotman A, Metzger ED (1996): Medications in the treatment of eating disorders. Psychiatry Clin North Am 19:739-754

Jimerson DC, Wolfe BE, Metzger ED, Finkelstein DM, Cooper TB, Levine JM (1997): Decreased serotonin function in bulimia nervosa. Arch Gen Psychiatry 54:529-534

Kaye WH, Greeno CG, Moss H, Fernstrom J, Fernstrom M, Lilenfeld LR, Weltzin TE, Mann JJ (1998): Alterations in serotonin activity and psychiatric symptoms after recovery from bulimia nervosa. Arch Gen Psychiatry 55:927-935

Kissileff HR, Wentzlaff TH, Guss JL, Walsh BT, Devlin MJ, Thornton JC (1996): A direct measure of satiety disturbance in patients with bulimia nervosa. Physiol Behav 60:1077-1085

Krebs HA, Cheng LK, Wright GJ (1984): Determination of fenfluramine and norfenfluramine in plasma using a nitrogen-sensitive detector. J Chromat 310:412-417

LaChaussee JL, Kissileff HR, Walsh BT, Hadigan CM (1992): The single-item meal as a measure of binge-eating behavior in patients with bulimia nervosa. Physiol Behav 51:593-600

Leibowitz SF, Weiss GF, Suh JS (1990): Medial hypothalamic nuclei mediate serotonin's inhibitory effect on feeding behavior. Pharmacol Biochem Behav 37:735-742

Levitan RD, Kaplan AS, Joffe RT, Levitt AJ, Brown GM (1997): Hormonal and subjective responses to intravenous meta-chlorophenylpiperazine in bulimia nervosa. Arch Gen Psychiatry 54:521-527
Levy AB, Dixon KN, Malarkey WB (1988): Pituitary response to TRH in bulimia. Biol Psychiatry 23:476-484

Lohman TG, Roche AF, Martorell R (1988): Anthropometric Standardization Reference Manual, 1st ed. Champaign, IL, Human Kinetics Books

Mitchell JE, Laine DC (1985): Monitored binge-eating behavior in patients with bulimia. Int J Eat Disord 4:177-183

Monteleone P, Brambilla F, Bortolotti F, Ferraro C, Maj M (1998): Plasma prolactin response to D-fenfluramine is blunted in bulimic patients with frequent binge episodes. Psychol Med 28:975-983

Obarzanek E, Lesem MD, Goldstein DS, Jimerson DC (1991): Reduced resting metabolic rate in patients with bulimia nervosa. Arch Gen Psychiatry 48:456-462

Oldman AD, Walsh AES, Salkovskis P, Fairburn CG, Cowen PJ (1995): Biochemical and behavioural effects of acute tryptophan depletion in abstinent bulimic subjects: A pilot study. Psychol Med 25:995-1001

Olmsted MP, Kaplan AS, Rockert W (1994): Rate and prediction of relapse in bulimia nervosa. Am J Psychiatry 151:738-743

Pirke KM, Pahl J, Schweiger U, Warnhoff M (1985): Metabolic and endocrine indices of starvation in bulimia: A comparison with anorexia nervosa. Psychiatry Res 15:33-39

Smith KA, Fairburn CG, Cowen PJ (1999): Symptomatic relapse in bulimia nervosa following acute tryptophan depletion. Arch Gen Psychiatry 56:171-176

Society of Actuaries, Association of Life Insurance Medical Directors of America (1980): Build Study, 1979. Chicago, Society of Actuaries

Spielberger CD (1983): Manual for the State-Trait Anxiety Inventory (STAI-Form-Y). Palo Alto, CA, Consulting Psychologist Press

Spitzer RL, Endicott J, Robins E (1978): Research diagnostic criteria: Rationale and reliability. Arch Gen Psychiatry 35:773-782

SPSS $^{\circledR} 9.0$ [Computer Software] (1999): Chicago, IL, SPSS Inc

Tecott LH, Sun LM, Akana SF, Strack AM, Lowenstein DH, Dallman MF, Julius D (1995): Eating disorder and epilepsy in mice lacking 5-HT2c serotonin receptors. Nature 374:542-546

Weltzin TE, Fernstrom MH, Fernstrom JD, Neuberger SK, Kaye WH (1995): Acute tryptophan depletion and increased food intake and irritability in bulimia nervosa. Am J Psychiatry 152:1668-1671

Weltzin TE, McConaha C, McKee M, Hsu LKG, Perel J, Kaye WH (1991): Circadian patterns of cortisol, prolactin, and growth hormone secretion during binging and vomiting in normal weight bulimic patients. Biol Psychiatry 30:37-48

Wolfe BE, Jimerson DC, Levine JM (1994a): Impulsivity ratings in bulimia: relationship to binge eating behaviors. Int J Eat Disord 15:289-292

Wolfe BE, Jimerson DC, Metzger ED, Levine JM (1994b): Serotonergic challenge responses in women with a history of bulimia nervosa [Abst]. Biol Psychiatry 35:736-737

Wolfe BE, Metzger ED, Jimerson DC (1997): Research update on serotonin function in bulimia nervosa and anorexia nervosa. Psychopharmacol Bull 33:345-354 